\title{
RELAÇÃO DA COMPOSIÇÃO QUÍMICA DO LEITE COM O NÍVEL DE PRODUÇÃO, ESTÁDIO DE LACTAÇÃO E ORDEM DE PARIÇÃO DE VACAS MESTIÇAS
}

\author{
Relation of chemical composition of milk with the level of \\ production stage of lactation and parity order cows crossbred
}

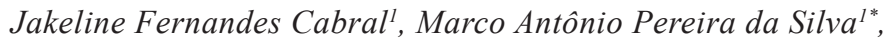 \\ Thiago Soares Carvalho ${ }^{I}$, Rafaella Belchior Brasi $1^{1}$, Julliano Costa Garcia ${ }^{1}$, \\ Luiz Eduardo Costa do Nascimentol
}

\begin{abstract}
RESUMO
O objetivo do estudo foi comparar a composição físico-química do leite in natura de vacas mestiças em diferentes níveis de produção e a influência da ordem de parição e o estádio de lactação na composição química do leite de vacas de alta produção. A pesquisa foi realizada no município de Rio Verde no sudoeste do estado de Goiás. Foram coletadas 784 amostras de leite in natura de vacas mestiças no experimento I que foram divididas em três níveis de produção. No segundo procedimento experimental, as amostras coletadas resultaram em 657 amostras de leite in natura, sendo divididas em 4 fases do estádio de lactação das vacas e divididas em oito ordens de parição, no qual novilhas de primeira cria correspondiam a $1^{\mathrm{a}}$ ordem e vacas multíparas a partir da $2^{\mathrm{a}}$ cria até a oitava. Para análise de variância e comparação de média utilizou-se o delineamento inteiramente casualizado e o teste de Tukey a 5\% de significância utilizando o software SISVAR. Os diferentes níveis de produção resultaram em diferenças físico-químicas dos componentes do leite, portanto, os percentuais encontrados podem não só estar relacionados com o nível, mas também ao estádio de lactação e ordem de parição do animal.
\end{abstract}

Palavras-chave: controle leiteiro; números de partos; lactação; componentes do leite.

1 Instituto Federal de Educação, Ciência e Tecnologia Goiano, Campus Rio Verde, Rodovia Sul Goiana, Km 01, s/n, Zona Rural, 75901-970, Rio Verde, GO, Brasil. E-mail: marcotonyrv@yahoo.com.br

* Autor para correspondência. 


\begin{abstract}
The aim of the study was to compare the physical and chemical composition of the raw milk of crossbred cows in different production levels and influence of parity order and stage of lactation on milk chemical composition of high producing cows. The search was conducted in the municipality of Rio Verde in southwestern Goiás, 784 samples were collected from raw milk of crossbred cows in experiment I and were divided into three levels of production. In the second experimental procedure, the samples resulted in 657 samples of raw milk, being divided into 4 stages of lactation stage of the cows and divided into eight parity order in which first-calf heifers corresponded to first order, and multiparous cows from the second until the eighth creates. For analysis of variance and mean comparison was used lineation all casualized and we used the Tukey test at 5\% probability, using the software SISVAR. The different levels of production resulted in physico-chemical differences of the constituents of milk, thus the percentages found may be related not only the level but also at the stage of lactation and parity order of the animals.
\end{abstract}

Keywords: milk control, numbers of births, lactation, chemical composition.

\section{INTRODUÇÃO}

A qualidade do leite pode ser estimada através da composição físico-química, pois é de grande importância identificar animais que produzam leite de melhor qualidade, já que a grande parte das indústrias paga pela qualidade da matéria-prima recebida. Os parâmetros que são mais pesquisados e que denotam a qualidade do leite, além de apresentar uma maior variação, são: gordura, proteína, lactose e células somáticas. Assim, pode ser compreendido que a composição centesimal do leite pode ser influenciada e variar quanto ao nível de produção, ordem de parto, estádio de lactação, raça, alimentação, idade, temperatura ambiental, estação do ano, fatores fisiológicos, patológicos, quartos mamários, porção da ordenha e intervalo entre ordenhas (GONZÁLES et al., 2001).

Entretanto, devem ser abordados criteriosamente os efeitos que causam uma maior variação e tentar minimizá-los, pois Pales; Figueiras (2005) verificaram que quanto maior a quantidade de leite que uma fêmea bovina produz, menor será a porcentagem de gordura, proteínas e minerais.

Souza et al. (2009) estudando as principais causas de infecções que acometem vacas em lactação, concluíram que o aumento da contagem de células somáticas (CCS) no rebanho foi devido ao número de animais contaminados com microrganismos causadores de mastite e que o estádio de lactação e a ordem de parto das vacas também influenciaram o aumento da CCS no leite.

Como descrito acima, vários fatores podem influenciar na composição físico-química do leite, portanto, o objetivo do estudo foi comparar a composição físico-química do leite in natura de vacas mestiças em diferentes níveis de produção e a influência da ordem de parição e estádio de lactação na composição química do leite de vacas de alta produção.

\section{MATERIAL E MÉTODOS}

A pesquisa foi realizada em uma propriedade leiteira localizada no município de Rio Verde, no Sudoeste do Estado de Goiás, 
no período de março de 2012 a maio de 2012. Foram coletadas amostras de leite in natura individuais de 180 vacas mestiças.

\section{Procedimento experimental I}

Foram coletadas 784 amostras de leite in natura de vacas mestiças e divididas em três níveis de produção: nível $1<15 \mathrm{~kg}$; nível $2=$ 15 a $25 \mathrm{~kg}$; nível $3>25 \mathrm{~kg}$. Os animais foram ordenhados duas vezes ao dia, às 4 horas e às 16 horas, correspondendo ao intervalo de 12 horas entre ordenhas.

\section{Procedimento experimental II}

Foram coletadas amostras uma vez por semana, em seis semanas, realizadas no período chuvoso de um rebanho de 180 vacas mestiças. As amostras coletadas resultaram em 657 amostras de leite in natura, sendo divididas em 4 fases do estádio de lactação das vacas, o que correspondeu a dados do estádio de lactação do $1^{\circ}$ ao $115^{\circ}$ dia, do $116^{\circ}$ ao $200^{\circ}$ dia, do $201^{\circ}$ ao $315^{\circ}$ dia e acima de 316 dias.

Para a ordem de parição, as amostras foram divididas em oito estádios, no qual novilhas de primeira cria correspondiam a $1^{\mathrm{a}}$ ordem, e vacas multíparas a partir da $2^{\mathrm{a}}$ cria até a oitava, correspondendo a $2^{\mathrm{a}}, 3^{\mathrm{a}}, 4^{\mathrm{a}}, 5^{\mathrm{a}}$, $6^{\mathrm{a}}, 7^{\mathrm{a}}$ e $8^{\mathrm{a}}$ ordem respectivamente.

\section{Procedimentos de coleta das amostras de leite in natura}

A ordenha foi realizada em circuito fechado em ordenhadeira mecânica tipo escama de peixe, com 20 conjuntos de teteiras e coletores de leite acoplados para mensuração do volume de leite produzido.

Os animais foram distribuídos conforme o nível de produção, o que predominava vacas com uma maior produção no primeiro lote, vacas com nível médio de produção no segundo lote e no terceiro lote vacas e novilhas com baixo nível de produção.
O manejo de ordenha utilizado foi o método tradicional, foram desprezados os três primeiros jatos de leite em caneca de fundo preto, em seguida, com o auxílio de um aplicador com retorno, os tetos foram imersos em solução, a base de iodo glicerinado a $0,25 \%$, em seguida foram secos com toalhas de papel descartáveis.

Foi realizada a ordenha completa e ininterrupta do leite. Com o término da ordenha, uma amostra representativa do total da produção de leite foi armazenada no coletor e o volume produzido foi anotado em uma ficha de campo. Estes procedimentos foram realizados tanto na primeira ordenha, quanto na segunda. As amostras foram coletadas em frascos de $40 \mathrm{~mL}$ contendo conservante bronopol $^{\circledR}$.

A metodologia de coleta constituiu na amostragem de um pool ( $2 / 3$ de leite do frasco na primeira ordenha e $1 / 3$ de leite do frasco na segunda ordenha do dia). Ao término da ordenha, aplicava-se a solução pós-ordenha, cuja base, foi o iodo glicerinado a $0,25 \%$.

As amostras de leite in natura foram homogeneizadas, armazenadas em caixas isotérmicas lacradas com gelo e transportadas para o Laboratório de Qualidade do Leite do Centro de Pesquisa em Alimentos da Escola de Veterinária e Zootecnia da Universidade Federal de Goiás, onde foram submetidas às análises eletrônicas.

\section{Análises eletrônicas da composição química do leite}

Os teores de gordura, proteína, lactose, extrato seco desengordurado (ESD) e extrato seco total (EST) foram determinados através do princípio analítico que se baseia na absorção diferencial de ondas infravermelhas pelos componentes do leite, utilizando o equipamento Milkoscan 4000 (Foss Electric A/S. Hillerod, Denmark). Os resultados foram expressos em porcentagem $(\%)$. 
Os teores de uréia e caseína foram determinados através do princípio analítico que baseia-se na absorção diferencial de ondas infravermelhas, transformada por Fourier FTIR, utilizando o equipamento Lactoscope (Delta instruments). Os resultados de caseína foram expressos em porcentagem (\%) e os resultados de uréia foram expressos em (mg/dL).

\section{Contagem de células somáticas}

A análise de células somáticas (CS), cujo princípio analítico se baseia na citometria de fluxo foi realizada através do equipamento Fossomatic 5000 Basic (Foss Electric A/S. Hillerod, Denmark). O resultado foi expresso em $\mathrm{CS} / \mathrm{mL}$.

\section{Análise estatística}

Para os experimentos foi utilizado delineamento experimental inteiramente casualizado (DIC) com dados desbalanceados, coletados e submetidos à análise de variância considerando-se a média dos níveis de produção, de estádio de lactação e ordem de parição. Para CCS, devido à falta de distribuição normal, foi realizada a transformação dos dados utilizando-se a função logarítmica. Em seguida, realizou-se a análise de variância e para comparação de médias de grupos experimentais, utilizou-se o teste de Tukey a $5 \%$ de probabilidade, utilizando-se o software Sisvar (Ferreira, 2010).

\section{RESULTADO E DISCUSSÃO}

Conforme pode ser observado na Tabela 1 , o percentual de gordura e proteína variou nos três níveis de produção, no entanto, a maior média foi encontrada no nível $1<15$ o que demonstra, quanto menor a produção de leite da vaca, maior é a concentração de gordura e proteína no leite. Campos et al., (2006) verificaram que a tendência observada é que o teor de gordura diminui quando a produção aumenta, o mesmo acontece com a lactose, porém este segundo componente é menos afetado com a oscilação do volume de leite.

Resultados iguais foram obtidos por Cabral (2012), onde ordenhas em sistemas leiteiros de duas e três ordenhas diárias, a concentração de gordura sempre foi maior quando a produção de leite era menor. Este fato pode ser explicado pelo efeito de diluição, onde com o aumento do volume de leite consequentemente ocorre a diminuição da concentração dos componentes (MOLLENHORST et al., 2011).

Houve variação na porcentagem de

Tabela 1 - Média de composição química do leite e contagem de células somáticas segundo três níveis de produção

\begin{tabular}{cccccc}
\hline \multirow{2}{*}{$\begin{array}{c}\text { Níveis de } \\
\text { Produção } \\
(\text { Litros })\end{array}$} & \multicolumn{3}{c}{ Composição Físico-química do leite (\%) } & CCS (x1000 \\
\cline { 2 - 4 } & Gordura & Proteína & Lactose & Uréia & CS/mL) \\
\hline$<15$ & $3,76^{\mathrm{a}}$ & $3,57^{\mathrm{a}}$ & $4,57^{\mathrm{a}}$ & $16,47^{\mathrm{a}}$ & $332,70^{\mathrm{a}}$ \\
$15-25$ & $3,50^{\mathrm{b}}$ & $3,29^{\mathrm{b}}$ & $4,59^{\mathrm{a}}$ & $15,05^{\mathrm{b}}$ & $213,84^{\mathrm{b}}$ \\
$>25$ & $3,11^{\mathrm{c}}$ & $2,96^{\mathrm{c}}$ & $4,55^{\mathrm{a}}$ & $15,18^{\mathrm{b}}$ & $253,33^{\mathrm{ab}}$ \\
CV $(\%)$ & 18,98 & 9,66 & 4,25 & 25,96 & 18,82 \\
\hline
\end{tabular}

Letras diferentes nas colunas apresentam diferença significativa $(\mathrm{p}<0,05)$, segundo teste de Tukey. CCS: Contagem de Células Somáticas. CV: Coeficiente de variação. 
proteína em todos os níveis de produção. $\mathrm{O}$ menor percentual de proteína apresentou-se no maior nível de produção, no entanto, a maior média de proteína foi observada no menor nível de produção. Zanela et al., (2006) avaliando a qualidade do leite em sistemas de produção na região Sul do país verificaram média de proteína de $3,42 \%$, cujo resultado foi semelhante ao desta pesquisa $(3,57 \%$ $2,96 \%$ ), ao avaliarem a produção de vacas Jersey. No entanto, com vacas Holandesas o valor médio de proteína observado por esses pesquisadores foi de 3,02\%. Estas porcentagens podem estar relacionadas a raças distintas do referido trabalho, sendo que o leite de vacas Jersey ocasionalmente apresenta uma maior concentração dos componentes do leite, já vacas Holandesas, na sua maioria, apresentam uma maior proporção de volume de leite produzido.

Dürr (2004) sugere que a proteína e a gordura são componentes que influenciam na produção de leite, entretanto, o teor proteico do leite tem menor variação do que a concentração de gordura.

No presente trabalho o teor de lactose não apresentou diferença significativa entre os níveis de produção. O mesmo foi observado por Cabral (2012) que avaliando a influência do método de coleta nos componentes químicos do leite, observou que a correlação entre lactose e produção de leite não é significativa, no entanto, deve ser levado em consideração que a produção leiteira varia em função da lactose. Eifert et al. (2006) relataram que a lactose é o principal e o mais importante componente osmótico do leite, por estar diretamente ligado a secreção de água e ao volume de leite produzido, além de ser um componente dependente de glicose para a sua síntese. No entanto, quando há menor proporção de lactose no leite, sugerese que provavelmente o animal esteja com deficiência de glicose, logo se observa a tendência a menor produção de leite.
Resultados inferiores ao do presente estudo foram obtidos por Brasil et al. (2012) na influência da ordenha mecânica e manual no teor de lactose e obtiveram resultados de lactose de $4,54 \%$ na ordenha manual e de $4,42 \%$ na ordenha mecânica. Carvalho et al. (2013) observou que a lactose foi o único componente que apresentou diferença estatística em função do método de ordenha. A maior porcentagem de lactose foi observada no leite ordenhado manualmente. No método de ordenha mecânica houve menor índice de lactose no leite e a também maior porcentagem de CCS (CARVALHO et al., 2013).

Quanto à ureia foi possível observar que os resultados no menor nível de produção foram diferentes e superiores aos níveis mais elevados de produção, assim pode ser levado em consideração que a variável ureia está associada diretamente com o percentual de proteína, o que reflete o manejo nutricional empregado na alimentação das vacas. Riemeier et al. (2004) verificaram que a quantidade de ureia no leite pode ser indicador de excessiva degradação de proteínas no rúmen. No entanto, a média dos níveis de ureia no leite recomendados pela literatura se encontram entre $12 \mathrm{mg} / \mathrm{dL}$ a $18 \mathrm{mg} / \mathrm{dL}$.

Quanto à análise de CCS o objetivo foi avaliar o estado sanitário das glândulas mamárias. Neste trabalho foi revelado que os teores de $\mathrm{CS} / \mathrm{mL}$ apresentaram diferença entre as amostras nos três níveis de produção. No nível $<15$ litros/dia foi observada a maior contagem verificada, o que pode ser explicado pela relação do aumento de células somáticas e a diminuição da produção de leite. Esta redução na produção de leite ocorre devido aos danos físicos às células secretoras da glândula mamária e também as alterações na permeabilidade vascular no alvéolo secretor (PALES; FILGUEIRAS, 2005).

A CCS das amostras de leite de vacas de maior produção $>25$ litros/leite/dia 
diferiram significativamente dos dois níveis comparados, o que pode demonstrar que a maior produção de leite pode estar relacionada com o aumento da CCS, pois o animal estaria passando por mudanças fisiológicas de secreção do leite. Voltolini et al., (2001) informaram que o início e final da lactação são as fases mais estressantes para a vaca, razão pela qual apresentará, naturalmente, uma elevada CCS.

De acordo com Cabral (2012) a relação entre produção de leite e CCS não é significativa em sistemas que realizam duas e três ordenhas diárias. Os dados foram contraditórios e numericamente o autor observou que houve um aumento gradativo de CCS conforme as ordenhas eram realizadas, no entanto, quando havia uma diminuição na produção de leite, o nível de CCS aumentava.

Na Tabela 2 está exposta a concentração dos componentes físico-químicos do leite de vacas mestiças de alta produção em relação ao estádio de lactação que estas vacas se encontram. Conforme apresentado na Tabela 2 , é possível observar que houve diferença $\mathrm{p}>0,05$ em todas as fases de lactação (início, meio e fim), em todos os componentes físicoquímicos do leite.

De acordo com os dados obtidos e avaliação do coeficiente de variação (\%), quatro das oitos variáveis estudadas apresentaram-se mais estáveis que as outras três variáveis. Estes resultados confirmam que houve uma precisão experimental de $57 \%$ para proteína, lactose, ESD e EST. Embora os componentes gordura, uréia e caseína se mostrassem mais instáveis que os outros componentes, estes ainda estão dentro do limite de variação quando a experimentação é realizada com animais que é de $20 \%$, exceto ureia.

De acordo com Campos et al. (2006) os valores de gordura exibem a maior variação entre os períodos de lactação das vacas de alta produção. Zafalon et al. (2005) relaciona a produção de leite ao estádio de lactação, o autor retrata que a produção de leite reduziu conforme o estádio de lactação avançou.

Quanto à influência do estádio de lactação sobre a gordura é possível verificar que quanto mais tempo o animal ficava em lactação, maior foi a concentração de gordura, chegando a 3,91\% em animais que passaram dos 316 dias de lactação, em relação aos animais que estavam na fase inicial de lactação que apresentaram média de 3,24\% de gordura.

As mesmas características da variação de gordura do presente estudo foram observadas por Pales et al., (2005) que observaram que logo após o parto o teor de sólidos no leite era muito alto, que pode ser explicado devido a necessidade de suprir nutricionalmente o recém-nascido, nas primeiras semanas de lactação. Este nível tende a cair e se estabilizar, pois com a diminuição da produção de leite o teor de gordura vai aumentando gradativamente.

Os percentuais de gordura do leite variam em função de diversos fatores: como o estádio de lactação, alimentação, raça, etc, tornando esta variável mais instável que os percentuais de proteína e lactose (PICININ et al., 2001). Zafalon et al. (2005) corroboraram que há uma redução da produção de leite conforme o estádio de lactação avançava.

A proteína apresentou o mesmo comportamento da gordura e a concentração aumentou gradativamente. Nas primeiras semanas de lactação foi registrado o menor índice de proteína, apresentando a menor média quando comparada ao final de lactação $(3,02 \%, 3,63 \%)$ respectivamente.

Já a concentração de lactose mantevese nos $4 \%$, com uma variação entre $4,64 \%$ e $4,57 \%$ no inicio e final da lactação respectivamente. O comportamento da lactose foi o contrário da gordura e proteína.

Resultados inferiores ao presente trabalho em relação ao teor lactose foram descritos por Oliveira et al. (2007) cuja variação 
foi de 4,35\% a 4,42\%. Já Silva et al. (2010) relataram valores semelhantes ao do presente estudo com média de 4,57\% em animais ordenhados manualmente, em propriedades leiteiras da região sudoeste de Goiás.

Para ESD e EST as maiores médias obtidas foram no final da lactação. Mesmo havendo uma alteração na concentração de ESD e EST sob a influência do estádio de lactação, todas as médias nas determinadas fases de lactação inicio, meio, fim ficaram dentro da média prevista pela legislação IN 62/2011 (BRASIL 2011).

Zafalon et al. (2005) estudaram a composição físico-química do leite em função da influência do estádio de lactação em quartos com e sem mastite subclínica. Foi descrito que o grupo com maior número de animais em lactação e com quartos mamários com mastite subclínica, a média do ESD foi de $8,4 \%$. Já em outro grupo, onde a média de ESD foi maior $(8,76 \%)$, também de animais com maior vida produtiva, os autores notaram que o ESD médio dos quartos mamários sadios foi superior.

A ureia e a caseína tiveram comportamentos semelhantes, sendo que as maiores médias foram no final da lactação. Concentrações de ureia no leite são consideradas bons indicadores de metabolismo e ingestão de proteínas em vacas leiteiras e atualmente são utilizadas como ferramentas para a avaliação de dietas (MOURO et al., 2002).

Como pode ser visto na Tabela 2, é fácil observar que a proteína, ureia e caseína do leite são componentes que executam o mesmo comportamento. No caso do estádio de lactação, as três variáveis aumentaram conforme aumenta a lactação. Este fato corrobora com Broderick; Clayton (1997) que relataram que de todo nitrogênio proteico, $80 \%$ é formado pela caseína e $20 \%$ pelas proteínas do soro. Do nitrogênio não proteico, o nitrogênio uréico perfaz entre $30 \%$ e $50 \%$ do total, sendo o restante formado principalmente pela creatinina, ácido úrico, amino ácidos e amônia.

Os teores de caseína possuem uma correlação positiva com o teor de proteína do leite, uma vez que a caseína representa cerca de $80 \%$ do total das proteínas contidas no leite. Portanto, no presente estudo, verificouse que nos estádios de lactação que apresentaram maiores teores de proteína, consequentemente apresentaram também maiores teores de caseína (HERMANSEN et al. 2004) e, por sua vez, a maiores teores de ureia.

$\mathrm{Na}$ Tabela 3 estão dispostos os valores de CCS sobre a influência do estádio de lactação.

As fases mais estressantes na vida da vaca que encontra-se em lactação é no início

Tabela 2 - Componentes químicos do leite em função do estádio de lactação de vacas mestiças

\begin{tabular}{cccccccc}
\hline \multirow{2}{*}{$\begin{array}{c}\text { Estádio de } \\
\text { lactação }\end{array}$} & Gordura & Proteína & Lactose & ESD & EST & Uréia & Caseína \\
\cline { 2 - 7 } & Gomposição físico-química (\%) & \\
\hline $1-115$ & $3,24^{\mathrm{c}}$ & $3,02^{\mathrm{c}}$ & $4,64^{\mathrm{a}}$ & $8,61^{\mathrm{d}}$ & $11,86^{\mathrm{c}}$ & $14,60^{\mathrm{c}}$ & $2,32^{\mathrm{d}}$ \\
$116-200$ & $3,36^{\mathrm{c}}$ & $3,24^{\mathrm{b}}$ & $4,56^{\mathrm{b}}$ & $8,78^{\mathrm{c}}$ & $12,15^{\mathrm{c}}$ & $15,02^{\mathrm{c}}$ & $2,51^{\mathrm{c}}$ \\
$201-315$ & $3,61^{\mathrm{b}}$ & $3,49^{\mathrm{a}}$ & $4,54^{\mathrm{b}}$ & $9,04^{\mathrm{b}}$ & $12,66^{\mathrm{b}}$ & $16,46^{\mathrm{b}}$ & $2,73^{\mathrm{b}}$ \\
$>316$ & $3,91^{\mathrm{a}}$ & $3,63^{\mathrm{a}}$ & $4,57^{\mathrm{b}}$ & $9,26^{\mathrm{a}}$ & $13,17^{\mathrm{a}}$ & $17,96^{\mathrm{a}}$ & $2,85^{\mathrm{a}}$ \\
$\mathrm{CV}(\%)$ & 18,71 & 8,99 & 4,04 & 4,65 & 7,27 & 25,27 & 10,85 \\
\hline
\end{tabular}

Letras diferentes nas colunas apresentam diferença significativa $(\mathrm{p}<0,05)$, segundo teste de Tukey. ESD: extrato seco desengordurado. EST: extrato seco total. CV: Coeficiente de variação. 
e final do estádio, portanto, é possível ser observado na Tabela 3 que no intervalo de lactação entre o $1^{\circ}$ e $115^{\circ}$ dia é o período onde o índice de CCS tem a menor concentração de 129,23 CS/mL. Já nos animais que passaram do limite de serem secados, a concentração de CCS é praticamente o triplo, apresentando uma média de 379,71 CS/mL, ou seja, quando > 316 dias de lactação. No entanto, observa-se que quanto mais tempo o animal permanece em lactação, mais afetada é a glândula mamária, pois a CCS é uma ferramenta de diagnóstico do estado sanitário da glândula mamária. De acordo com Medeiros et al. (2003) a CCS é uma ferramenta eficaz e bastante utilizada com o objetivo de monitorar a saúde da glândula mamária.

Resultados diferentes do presente trabalho foi relatado por Voltollini et al. (2001) que observou as maiores contagens de CS no inicio da lactação, o que contradiz o resultados do presente estudo. No entanto, o autor (VOLTOLLINI et al. 2001) também encontrou as maiores médias no fim de lactação, o que corroboram com os resultados presente estudo.

Langoni et al. (2009) corrobora que a CCS é utilizada como indicadora do nível de mastite e da presença de agentes contagiosos comprovando a importância da educação

Tabela 3 - Variação da contagem de células somáticas por $\mathrm{mL}$ em relação aos intervalos do estádio de lactação

\begin{tabular}{cccccc}
\hline & \multicolumn{5}{c}{ Estádio de lactação (dias) } \\
\cline { 2 - 5 } & $1-115$ & $116-200$ & $201-315$ & $>316$ & $\mathrm{CV}(\%)$ \\
\hline $\mathrm{CCS}$ & $129,23^{\mathrm{c}}$ & $257,51^{\mathrm{b}}$ & $287,88^{\mathrm{ab}}$ & $379,71^{\mathrm{a}}$ & 117,53 \\
\hline $1000 \times \mathrm{CS} / \mathrm{mL}$ & & & & & \\
\hline
\end{tabular}

Letras diferentes nas colunas apresentam diferença significativa $(\mathrm{p}<0,05)$, segundo teste de Tukey. CCS: Contagem de Células Somáticas. CV: Coeficiente de variação.

Tabela 4 - Resultados da influência da ordem de parição na composição química do leite de vacas mestiças

\begin{tabular}{cccccccc}
\hline \multirow{2}{*}{$\begin{array}{c}\text { Ordem de } \\
\text { parição }\end{array}$} & \multicolumn{7}{c}{ Composição química $(\%)$} \\
\cline { 2 - 7 } & Gordura & Proteína & Lactose & ESD & EST & Uréia & Caseína \\
\hline $1^{\mathrm{a}}$ & $3,58^{\mathrm{ab}}$ & $3,36^{\mathrm{ab}}$ & $4,69^{\mathrm{a}}$ & $9,06^{\mathrm{a}}$ & $12,65^{\mathrm{ab}}$ & $15,83^{\mathrm{a}}$ & $2,62^{\mathrm{ab}}$ \\
$2^{\mathrm{a}}$ & $3,39^{\mathrm{b}}$ & $3,30^{\mathrm{abc}}$ & $4,58^{\mathrm{ab}}$ & $8,87^{\mathrm{ab}}$ & $12,27^{\mathrm{bc}}$ & $16,34^{\mathrm{a}}$ & $2,56^{\mathrm{bc}}$ \\
$3^{\mathrm{a}}$ & $3,47^{\mathrm{b}}$ & $3,35^{\mathrm{ab}}$ & $4,52^{\mathrm{b}}$ & $8,85^{\mathrm{ab}}$ & $12,33^{\mathrm{bc}}$ & $15,63^{\mathrm{b}}$ & $2,60^{\mathrm{abc}}$ \\
$4^{\mathrm{a}}$ & $3,28^{\mathrm{bc}}$ & $3,06^{\mathrm{bc}}$ & $4,55^{\mathrm{b}}$ & $8,58^{\mathrm{bc}}$ & $11,86^{\mathrm{cd}}$ & $15,70^{\mathrm{a}}$ & $2,36^{\mathrm{cd}}$ \\
$5^{\mathrm{a}}$ & $3,30^{\mathrm{bc}}$ & $3,19^{\mathrm{abc}}$ & $4,35^{\mathrm{c}}$ & $8,50^{\mathrm{c}}$ & $11,80^{\mathrm{cd}}$ & $12,30^{\mathrm{b}}$ & $2,47^{\mathrm{bcd}}$ \\
$6^{\mathrm{a}}$ & $2,86^{\mathrm{c}}$ & $2,95^{\mathrm{c}}$ & $4,58^{\mathrm{ab}}$ & $8,47^{\mathrm{c}}$ & $11,34^{\mathrm{d}}$ & $13,50^{\mathrm{ab}}$ & $2,25^{\mathrm{d}}$ \\
$7^{\mathrm{a}}$ & $4,09^{\mathrm{a}}$ & $3,54^{\mathrm{a}}$ & $4,60^{\mathrm{ab}}$ & $9,16^{\mathrm{a}}$ & $13,25^{\mathrm{d}}$ & $15,24^{\mathrm{ab}}$ & $2,83^{\mathrm{a}}$ \\
$8^{\mathrm{a}}$ & $3,49^{\mathrm{b}}$ & $3,35^{\mathrm{ab}}$ & $4,57^{\mathrm{ab}}$ & $8,90^{\mathrm{ab}}$ & $12,40^{\mathrm{bc}}$ & $13,85^{\mathrm{ab}}$ & $2,59^{\mathrm{abc}}$ \\
$\mathrm{CV}(\%)$ & 19,06 & 10,32 & 3,72 & 4,79 & 7,53 & 25,67 & 12,18 \\
\hline
\end{tabular}

Letras diferentes nas colunas apresentam diferença significativa $(p<0,05)$, segundo teste de Tukey. ESD: extrato seco desengordurado. EST: extrato seco total. CV: coeficiente de variação. 
sanitária, pois a falta de higiene dentro da sala de ordenha e a carência de manejo prédipping e pós-dipping propiciam grande problema na obtenção do leite de boa qualidade.

Na Tabela 4 está disposto a variação dos componentes químicos do leite e a ordem de parição de vacas mestiças de alta produção.

De acordo com os resultados da influência da ordem de parição na composição química do leite, observa-se uma maior variação dos componentes quando comparados ao estádio de lactação e volume de leite produzido pelos animais.

Houve uma grande variação no percentual de gordura. Sendo a gordura o componente do leite que apresenta a maior amplitude de variação de acordo com Peres (2001). No entanto, no presente trabalho, a variação da gordura foi de $2,86 \%$ e $4,09 \%$, sendo que a menor média foi influenciada pela $6^{\mathrm{a}}$ parição e a maior média pela $7^{\mathrm{a}}$ parição, podendo ser levado em consideração o maior número de partos. Portanto é possível notar que a variação do percentual de gordura ocorreu entre a partir do sexto ao oitavo parto, o que pode representar idade avançada destas vacas em lactação.

Quanto à proteína, as médias foram semelhantes às médias de gordura, variando entre $2,95 \%$ e $3,54 \%$, onde estas variações ocorreram no sexto e no sétimo parto, demonstrando uma maior instabilidade neste período em que se encontra a vaca.

A lactose pouco variou ficando dentro dos parâmetros normais, o que corresponde a maior média no primeiro parto de $4,69 \%$ e a menor média $4,35 \%$ no quinto parto.

Em relação ao ESD, verifica-se que as médias ficaram dentro do padrão exigido pela legislação IN 62/2011, com média mínima de $8,4 \%$ (BRASIL, 2011). No entanto, houve médias acima de $9 \%$ de ESD no leite de vacas primíparas e de vacas multíparas com sete partos. Pode-se dizer que há uma oscilação dos parâmetros de ESD tanto no início da vida produtiva das vacas, quanto no final. O mesmo é observado nas médias de EST, onde a oscilação dos resultados foram maiores no início e final da vida produtiva das vacas com mais de sete partos que pode refletir mudanças fisiológicas das glândulas mamárias, quando muito exigida.

Resultados da porcentagem de ureia e caseína oscilaram bastante e esta variação pode estar relacionada a nutrição das vacas. Brasil (2012) corrobora que níveis de ureia abaixo de $12 \mathrm{mg} / \mathrm{dL}$ e acima de $18 \mathrm{mg} / \mathrm{dL}$, podem refletir um inadequado manejo nutricional, de acordo com os níveis recomendados. Os resultados do presente trabalho ficaram $12,30 \%$ e 16,34\%. Estes parâmetros quando acima e abaixo do recomendado pode comprometer a qualidade do leite, que já vem sendo reconhecida através do pagamento extra para os produtores que fornecerem um produto com maior percentual de sólidos totais e que estejam dentro dos padrões estabelecidos pela Instrução Normativa $n^{\circ} 62$ (BRASIL 2011).

$\mathrm{Na}$ Tabela 5 estão dispostos os resultados da influência da ordem de parição sobre a CCS do leite de vacas mestiças de alta produção.

Tabela 5 - Resultados de contagem de células somáticas em relação ao número de partos de vacas mestiças

\begin{tabular}{cc}
\hline Número de Partos & CCS $1000 \times \mathrm{CS} / \mathrm{mL}$ \\
\hline 1 & $154,07^{\mathrm{c}}$ \\
2 & $196,60^{\mathrm{bc}}$ \\
3 & $364,22^{\mathrm{abc}}$ \\
4 & $196,32^{\mathrm{abc}}$ \\
5 & $213,43^{\mathrm{abc}}$ \\
6 & $52,66^{\mathrm{d}}$ \\
7 & $443,56^{\mathrm{ab}}$ \\
8 & $420,05^{\mathrm{a}}$ \\
CV $(\%)$ & 17,43
\end{tabular}

Letras diferentes na linha apresentam diferença significativa $(\mathrm{p}<0,05)$, segundo teste de Tukey. CCS: contagem de células somáticas. 
Os resultados de CCS, nos primeiros partos das vacas do experimento, apresentaram médias baixas, o que pode estar relacionada com a saúde das glândulas mamárias e pelo fato que são novilhas e estão entrando na lactação. Resultados diferentes foram inferidos por Voltolini et al. (2001) que observou que no primeiro parto, o pico da CCS ocorreu no oitavo dia pós-parto, sugerindo que elevadas CCS nesta fase poderiam estar associadas com mudanças fisiológicas para a secreção do leite, como, por exemplo, edema de úbere. Já na segunda ordem de parto, o pico de CCS ocorreu na secagem, onde estaria envolvida com a concentração das células somáticas em um menor volume de leite.

Quando as vacas chegaram ao sétimo parto, houve uma crescente contagem de células que apresentam valores de 443,56 CS/ $\mathrm{mL}$ no sétimo parto e $420,05 \mathrm{CS} / \mathrm{mL}$ no oitavo parto. É possível observar que os animais que estão, há mais tempo na lactação, podem estar passando por mudanças fisiológicas ou até mesmo sanitárias, pois animais que estão há muito tempo em lactação estão sujeitos a contaminação por microrganismos patogênicos e até mesmo com enfermidade no epitélio glandular.

\section{CONCLUSÕES}

A composição físico-química do leite diferiu entre os níveis de produção das vacas, provavelmente pelo ao aumento do volume de leite produzido, o que resultou em uma consequente redução da concentração dos componentes.

O estádio de lactação influenciou diretamente na composição físico-química do leite das vacas utilizadas no experimento. De acordo com os dados obtidos é possível afirmar que o teor da maior parte dos componentes físico-químicos foi maior nas vacas que estavam no final da lactação e principalmente aquelas que estavam em lactação por mais de
316 dias. Estes dados mostram a necessidade de um manejo adequado e a importância do período de descanso de aproximadamente 90 dias, que são necessários para a recuperação da glândula mamária.

Para a ordem de parição deve-se ter uma atenção maior, pois a variação dos componentes é muito grande em função da quantidade de partos que a vaca já teve. Conforme visto, observa-se que a maior diferença no percentual dos componentes é quando as vacas passam do sétimo parto, no entanto, é correto ter um controle quanto a ordem de parto para avaliar se é rentável uma vaca permanecer por tanto tempo no plantel.

\section{REFERÊNCIAS}

BRASIL, R. B. et al. Avaliação da Qualidade do Leite Cru em Função do Tipo de Ordenha e das Condições de Transporte e Armazenamento. Revista Instituto Laticínio Cândido Tostes, v. 67, n. 389, p. 34-42, 2012.

BRASIL. Ministério da Agricultura, Pecuária e Abastecimento. Instrução Normativa $\mathrm{n}^{\circ}$ 62, de 29 de dezembro de 2011. Aprova o Regulamento Técnico de Produção, Identidade e Qualidade do Leite tipo A, o Regulamento Técnico de Identidade e Qualidade de Leite Cru Refrigerado, o Regulamento Técnico de Identidade e Qualidade de Leite Pasteurizado e o Regulamento Técnico da Coleta de Leite Cru Refrigerado e seu Transporte a Granel, em conformidade com os Anexos desta Instrução Normativa. Diário Oficial da República Federativa do Brasil, 30 dez. 2011. Seção 1, p. 6.

BRODERICK, G. A.; CLAYTON, M. K. A Statistical Evaluation Of Animal And $\mathrm{Nu}$ tritional Factors Influencing Concentration Of Milk Urea Nitrogen. Journal of Dairy Science, v. 11, n. 80, 2964-711997. 
CABRAL, J. F. Influência do método de coleta na composição química e contagem de células somáticas do leite de vacas de alta produção. 2012.45 f. Dissertação (mestrado) - Instituto Federal Goiano, Rio Verde, GO, 2012.

CAMPOS, R. et al. Indicadores do ambiente ruminal e suas relações com a composição do leite e células somáticas em diferentes períodos da primeira fase da lactação em vacas de alta produção. Ciência Rural, v. 2, n. 36, 2006.

CARVALHO, T. S. Qualidade do Leite Cru Refrigerado Obtido Através de Ordenha Manual e Mecânica. Revista Instituto Laticínio Cândido Tostes, n. 68, v. 390, p. 5-11, 2013.

DÜRR, J. W. Programa nacional de melhoria da qualidade do leite: uma oportunidade única. In: Dürr J. W., Carvalho M. P., Santos M. V. (Eds.) O compromisso com a qualidade do leite no Brasil. Passo Fundo: Editora Universidade de Passo Fundo, p. 38-55, 2004.

EIFERT, E. C. et. al. Consumo, produção e composição do leite de vacas alimentadas com óleo de soja e diferentes fontes de carboidratos na dieta1. Revista Brasileira Zootecnia, v. 35, n. 1, p. 211-218, 2006.

GONZÁLEZ, F. H. D. et al. Uso do leite para monitorar a nutrição e o metabolismo de vacas leiteiras. Porto Alegre: Gráfica, 77p, 2001.

HERMANSEN, J. E. et al. Effect of the levels of fertilizer, grass and supplementary feeds on nitrogen composition and renneting properties of milk from cows at pasture. Journal of Dairy Research, v. 61, n. 2, p. 1979-1989, 2004.

LANGONI, H. et al. Aspectos Citológicos e
Microbiológicos do Leite em Propriedades no Sistema Orgânico de Produção. Pesquisa Veterinária Brasileira, v. 29, n. 11, p. 881886. 2009.

MEDEIROS, E. S. et al. Avaliação do exame micro biológico, California Mastitis Test e Somaticell ${ }^{\circledR}$ no diagnóstico da mastite subclínica em bovinos leiteiros. Revista de Medicina Veterinária, v. 2, n. 2, p. 16-22, 2008.

MOLLENHORST, $\mathrm{H}$. et al. The relationship between milking interval and somatic cell count in automatic milking systems. Journal of Dairy Science, v. 94, n. 9, p. 4531-4537, 2011.

MOURO, G. F. et al. substituição do milho pela farinha de mandioca de varredura em dietas de cabras em lactação: fermentação ruminal e concentrações de uréia plasmática e no leite. Revista Brasileira de Zootecnia, v. 31, n. 4, p. 1840-1848, 2002.

OLIVEIRA, M. A. et al. Produção e composição do leite de vacas alimentadas com dietas com diferentes proporções de forragem e teores de lipídeos. Arquivo Brasileiro de Medicina Veterinária e Zootecnia, v. 59, n. 3, p. 759-766, 2007.

PALES, A. P. et al. A importância da contagem de células somáticas e contagem bacteriana total para a melhoria da qualidade do leite no Brasil. Revista Eletrônica Faculdade Montes Belos, v. 1, n. 2, p. 162-173, 2005.

PERES, J. R. O leite como ferramenta do monitoramento nutricional. In: Gonzalez, F. H. D.; Dürr, J. W.; Fontanele, R. (Eds.). Uso do leite para monitorar a nutrição e o metabolismo de vacas leiteiras. Porto Alegre: Biblioteca Setorial da FV - UFRGS, 2001: 29-43. 
PICININ, L. C. A. et al. Qualidade físicoquímica de leite cru resfriado. In: $\mathrm{CON}$ GRESSO NACIONAL DE LATICÍNIOS, 18, 2001, Juiz de Fora. Anais... Juiz de Fora: EPAMIG/ILCT, 2001, p. 294-300.

RIEMEIER, A. et al. Influence of the ruminal N-balance on rumen metabolism. Journal Animal and Feed Sciences, v. 13, p. 191194, 2004.

SILVA, M. et al. Variação da qualidade do leite cru refrigerado em função do período do ano e do tipo de ordenha. Revista do Instituto Adolfo Lutz, v. 69, n. 1, p. 112-118, 2010.

SOUZA, G. N. et al. Variação da contagem de células somáticas em vacas leiteiras de acordo com patógenos da mastite. Arquivo Brasileiro de Medicina Veterinária e Zootecnia, v. 61, n. 5, p. 1015-1020, 2009.

VOLTOLINI, T. V. et al. Influência dos estádios de lactação sobre a contagem de células somáticas do leite de vacas da raça holandesa e identificação de patógenos causadores de mastite no rebanho. Acta Scientiarum, v. 23, n. 4, p. 961-966, 2001.

ZAFALON, L. F. et al. Alterações da composição e da produção de leite oriundo de quartos mamários de vacas com e sem mastite subclínica de acordo com o estádio e o número de lactações. Arquivo do Instituto Biológico, v. 72, n. 4, p. 419-426, 2005.

ZANELA, M. B. Qualidade do leite em sistemas de produção na região Sul do Rio Grande do Sul. Pesquisa Agropecuária Brasileira, v. 41, n. 1, p. 153-159, 2006. 